\title{
DIFFERENT PATTERNS OF ATHEROSCLEROTIC REMODELING IN THE THORACIC AND ABDOMINAL AORTA
}

Luiz Alberto Benvenuti, Ronaldo Yukinori Onishi, Paulo Sampaio Gutierrez, and Maria de Lourdes Higuchi

Benvenuti LA, Onishi RY, Gutierrez PS, Higuchi M de L. Different patterns of atherosclerotic remodeling in the thoracic and abdominal aorta. Clinics. 2005;60(5):355-60.

PURPOSE: To investigate the relationship between the vascular diameter and the extent and histologic characteristics of atherosclerosis in the thoracic and abdominal aortas of patients who died of atherosclerotic disease.

METHOD: We measured the vascular diameter and evaluated the percentage atrophy of the medial layer of the thoracic and abdominal aortas of 19 patients who died due to atherosclerotic disease. The extent of plaques, calcification, ulceration, thrombosis, and the amount of fat in the plaques were evaluated semiquantitatively.

RESULTS: Atherosclerosis was more severe in the abdominal than the thoracic aorta as indicated by the higher sum of the macroscopic scores $(P=.02)$ and the higher percentage atrophy of the medial layer $(P<.001)$. The diameter of the thoracic, but not of the abdominal aorta, correlated with age $(\mathrm{r}=0.56 ; P=.01)$, plaque score $(\mathrm{r}=0.59 ; P=.008)$, calcification score $(\mathrm{r}=0.749$; $P<.001)$, and fat score $(\mathrm{r}=0.48 ; P=.04)$. Multiple linear regression showed that age $(P=.06)$ and calcification score $(P=.001)$ were the parameters with the strongest association to thoracic aorta diameter.

CONCLUSION: There are some differences regarding atherosclerosis in the thoracic compared to the abdominal aorta. Progressive thoracic aorta atherosclerosis is associated with fat deposition in the plaques, inducing arterial dilation. In the abdominal aorta, atherosclerosis can either have a similar evolution or be associated with less fat deposition in the arterial wall, which would result in more rigidity, hindering compensatory arterial enlargement.

KEYWORDS: Aorta. Atherosclerosis. Arterial diameter. Remodeling. Morphometry.

Atherosclerotic lesions usually predominate in the branch ostia, bifurcations, and arterial bends, and they are directly related to arterial pressure and wall stress. ${ }^{1-3}$ Compensatory dilation, also known as positive remodeling, occurs in many atherosclerotic arteries, ${ }^{4,5}$ and is associated with better preservation of distal blood flow. In coronary arteries, positive remodeling is related to fat plaques and acute thrombosis, while negative remodeling, characterized by diminished vascular diameter, is associated with fibrous plaques and chronic myocardial ischemia.,

Laboratory of Pathology, Heart Institute (InCor), Hospital das Clínicas, Faculty of Medicine, University of São Paulo - São Paulo/SP, Brazil. Email: anpluiz@incor.usp.br

Received for publication on January 20, 2005.

Accepted for publication on May 09, 2005.
Aortic atherosclerosis predominates in the abdominal segment. In severe forms of the disease, either progressive dilation (aneurysm) or diffuse narrowing of the lumen may occur, the latter being associated with chronic ischemia of lower limbs. ${ }^{2}$ These two possibilities of pathologic changes in aortic diameter related to severe atherosclerosis have not been considered by previous investigations that established a direct correlation between the vascular diameter and the extent of lesions suggesting the occurrence of positive remodeling with the progression of atherosclerosis. ${ }^{8-10}$ The objective of this study was to separately evaluate the relationship between the aortic diameter in the thoracic and abdominal segments, and the extent and histological characteristics of atherosclerosis in patients presenting with atherosclerotic disease. 


\section{METHODS}

The aortas of 19 patients were collected at necropsies performed at the Heart Institute (InCor), University of São Paulo Medical School. Only patients with an age $\geq 18$ years and presenting with atherosclerosis or its complication as the main disease and cause of death were included in the study. Chronic ischemic heart disease was present in 17 out of the 19 patients $(90 \%)$, myocardial infarction with less than 10 days of evolution in $7(37 \%)$, cerebral vascular disease in $2(11 \%)$, systemic arterial hypertension in 18 (95\%), and diabetes mellitus in $8(42 \%)$. The aorta was longitudinally opened at the posterior margin and formalin-fixed.

\section{Macroscopic analysis}

Whole aortic rings with lengths of $1 \mathrm{~cm}$ were isolated from 2 locations: halfway between the origin of the left subclavian artery and the celiac trunk (thoracic segment) and between the celiac trunk and the bifurcation of the iliac arteries (abdominal segment). We measured the internal perimeter of the aortic rings and evaluated the extent of atherosclerotic plaque, calcification, thrombosis, and ulceration in a semiquantitative manner. This semiquantitative scoring system, ranging from 1 to 4 , was attributed to the extent of the atherosclerotic lesions based on the percentage of the inner surface of the rings occupied by them: 1, up to $25 \%$; 2 , from $26 \%$ to $50 \%$; 3 , from $51 \%$ to $75 \%$; and 4 , more than $75 \%$. The internal diameter of the aorta was calculated from the ratio between internal perimeter measurement and the $\pi$ parameter.

\section{Microscopic analysis}

Aortic rings were fixed in formalin, transversally sectioned, routinely processed for paraffin embedding, and sequentially sliced into sections (4-mm thickness). The amount of fat in the atherosclerotic plaques was evaluated from its negative image in Masson's trichrome-stained sections. A semiquantitative scoring system was applied including all atherosclerotic plaques in the sections: 0 , no fat detected; 1, small amount of fat; 2, moderate amount of fat; and 3, large amount of fat. The percentage atrophy of the medial layer was calculated from the ratio between its largest and smallest thickness, multiplied by 100 . For these measurements, we used the Verhoeff's stained sections and a computerized image analysis system adapted to an optical microscope.

Representative images of the histopathologic characteristics of the lesions are presented in Figure 1.
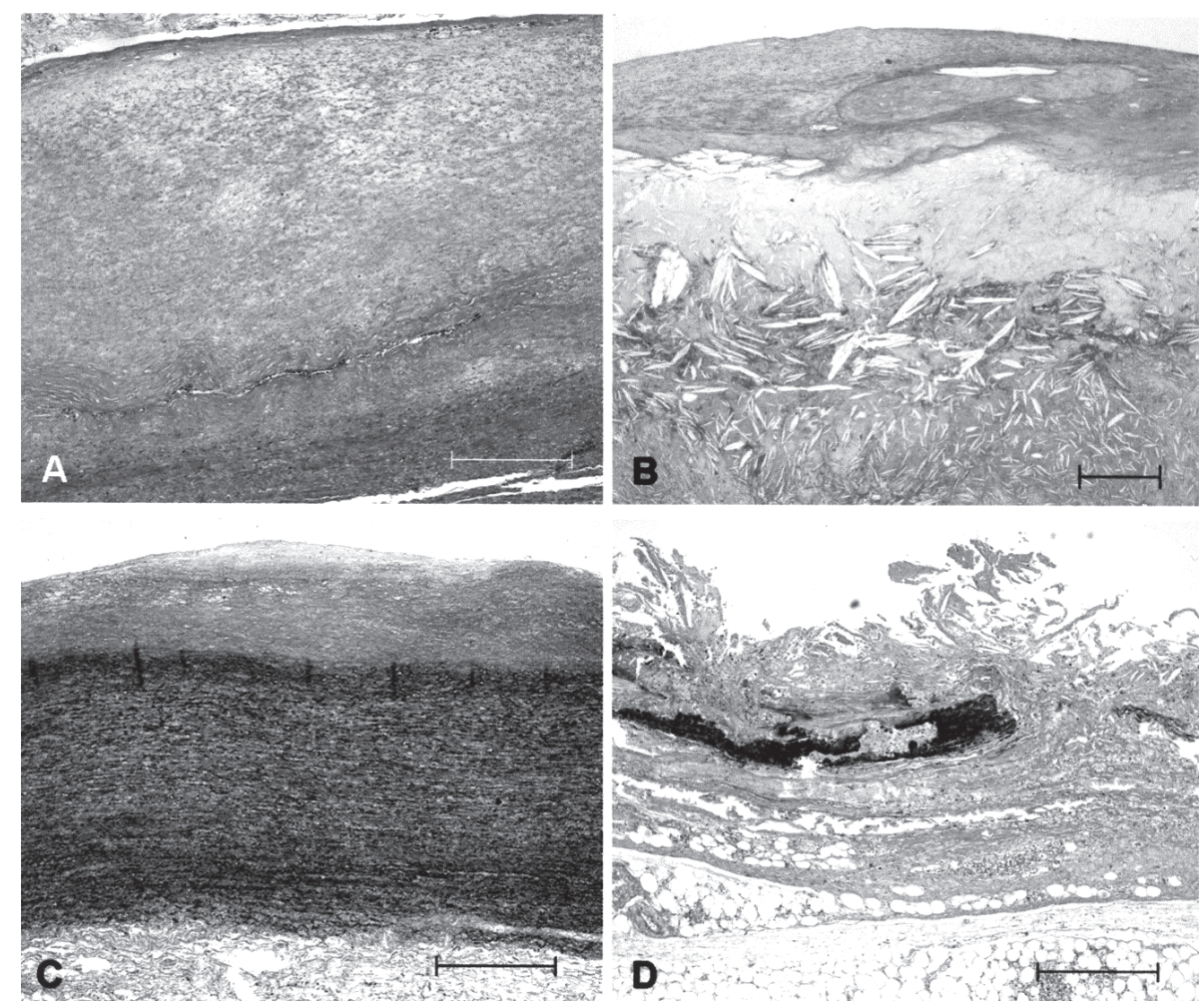

Figure 1 - Atherosclerotic lesions showing: (A) thick fibrous plaque; (B) fat plaque with many cholesterol clefts; (C) small fibrous plaque and preserved medial layer; (D) superficial ulceration and medial layer presenting massive destruction of elastic fibers. A and B Masson's trichrome stain; C and D Verhoeff's stain for elastic fibers. Bar $=500 \mu \mathrm{m}$ 
Table 1 - Gender, age, aortic diameter, semiquantitative scores, and percentage of medial layer atrophy of the thoracic and abdominal segments of the aorta

\begin{tabular}{|c|c|c|c|c|c|c|c|c|c|c|c|c|c|c|c|c|}
\hline \multirow[b]{2}{*}{$\#$} & \multirow[b]{2}{*}{ G } & \multirow[b]{2}{*}{$\mathrm{A}$} & \multicolumn{6}{|c|}{ Thoracic aorta } & \multicolumn{8}{|c|}{ Abdominal aorta } \\
\hline & & & $\overline{\mathrm{Dm}}$ & $\mathrm{Pl}$ & $\mathrm{C}$ & $\mathrm{U}$ & $\mathrm{T}$ & $\mathrm{F}$ & $\%$ Atr & $\mathrm{Dm}$ & $\mathrm{Pl}$ & $\mathrm{C}$ & $\mathrm{U}$ & $\mathrm{T}$ & $\mathrm{F}$ & $\%$ Atr \\
\hline 1 & $\mathrm{~F}$ & 69 & 1.81 & 3 & 2 & 2 & 1 & 3 & 100 & 1.37 & 4 & 2 & 3 & 2 & 3 & 100 \\
\hline 2 & M & 71 & 2.32 & 4 & 4 & 1 & 1 & 2 & 43 & 2.42 & 4 & 2 & 3 & 1 & 3 & 100 \\
\hline 3 & $\mathrm{~F}$ & 67 & 2.29 & 4 & 4 & 2 & 1 & 3 & 72 & 1.69 & 4 & 2 & 1 & 1 & 1 & 100 \\
\hline 4 & M & 78 & 1.97 & 4 & 3 & 2 & 1 & 1 & 60 & 1.46 & 4 & 2 & 2 & 1 & 2 & 48 \\
\hline 5 & $\mathrm{~F}$ & 68 & 2.04 & 3 & 2 & 1 & 1 & 2 & 45 & 1.43 & 4 & 4 & 2 & 1 & 3 & 81 \\
\hline 6 & M & 69 & 2.04 & 3 & 2 & 2 & 1 & 1 & 57 & 1.56 & 4 & 4 & 2 & 1 & 2 & 62 \\
\hline 7 & $\mathrm{~F}$ & 75 & 1.85 & 2 & 2 & 1 & 1 & 1 & 49 & 1.40 & 4 & 2 & 2 & 2 & 2 & 94 \\
\hline 8 & $\mathrm{M}$ & 76 & 2.29 & 4 & 3 & 2 & 1 & 2 & 87 & 2.20 & 4 & 4 & 2 & 1 & 3 & 100 \\
\hline 9 & $\mathrm{M}$ & 61 & 1.88 & 3 & 2 & 1 & 1 & 2 & 35 & 1.40 & 3 & 2 & 2 & 2 & 1 & 63 \\
\hline 10 & $\mathrm{M}$ & 72 & 2.23 & 4 & 3 & 1 & 1 & 2 & 32 & 1.37 & 4 & 4 & 2 & 2 & 1 & 80 \\
\hline 11 & M & 65 & 1.94 & 2 & 2 & 1 & 1 & 1 & 47 & 1.53 & 4 & 4 & 1 & 1 & 3 & 84 \\
\hline 12 & $\mathrm{M}$ & 50 & 1.50 & 2 & 1 & 1 & 1 & 0 & 43 & 1.24 & 3 & 2 & 1 & 1 & 1 & 100 \\
\hline 13 & $\mathrm{~F}$ & 81 & 2.01 & 4 & 2 & 1 & 1 & 1 & 45 & 1.50 & 4 & 3 & 1 & 1 & 1 & 55 \\
\hline 14 & $\mathrm{M}$ & 76 & 2.10 & 4 & 3 & 3 & 1 & 2 & 36 & 1.59 & 4 & 4 & 3 & 2 & 3 & 75 \\
\hline 15 & $\mathrm{M}$ & 69 & 2.04 & 2 & 2 & 1 & 1 & 1 & 58 & 1.88 & 4 & 2 & 2 & 1 & 2 & 96 \\
\hline 16 & $\mathrm{~F}$ & 72 & 2.04 & 4 & 3 & 1 & 1 & 1 & 58 & 1.27 & 4 & 4 & 2 & 1 & 2 & 69 \\
\hline 17 & $\mathrm{~F}$ & 75 & 2.07 & 4 & 3 & 2 & 1 & 1 & 61 & 1.40 & 4 & 4 & 2 & 1 & 1 & 68 \\
\hline 18 & $\mathrm{M}$ & 74 & 2.10 & 2 & 2 & 3 & 1 & 3 & 49 & 1.46 & 4 & 4 & 2 & 2 & 2 & 68 \\
\hline 19 & $\mathrm{M}$ & 69 & 2.04 & 4 & 4 & 2 & 3 & 3 & 66 & 1.50 & 2 & 1 & 2 & 1 & 3 & 100 \\
\hline
\end{tabular}

$\#=$ case number $; \mathrm{G}=$ gender; $\mathrm{A}=$ age $; \mathrm{Dm}=$ diameter $(\mathrm{cm}) ; \mathrm{Pl}=$ plaque score $; \mathrm{C}=$ calcification score $; \mathrm{U}=$ ulceration score; $\mathrm{T}=$ thrombosis score $\mathrm{F}=$ fat score; $\%$ Atr $=$ percentage atrophy of the medial layer; $\mathrm{M}=$ male; $\mathrm{F}=$ female.

\section{Statistical analysis}

Continuous and categorical variables obtained from the analysis of thoracic and abdominal aortic segments were compared using the paired $t$ test and the Wilcoxon test, respectively. The effect of gender on the values of continuous and categorical variables was evaluated using the $t$ test and the Mann-Whitney test, respectively. Linear regression and multiple linear regression (forward stepwise) were used to verify the relationship between the aortic diameter of both the thoracic and abdominal segments (dependent variable) and the remaining variables (independent variables). We considered $P$ values $\leq .05$ to indicate statistical significance.

\section{RESULTS}

Table 1 presents age, gender, diameter of thoracic and abdominal segments of the aorta, percentage atrophy of the medial layer, and semiquantitative scores of the cases. Age ranged from 50 to 81 years $(70.4 \pm 6.88$, mean $\pm S D)$, and 12 of the $19(63 \%)$ patients were male.

Table 2 shows diameters and percentage of medial layer atrophy (mean and standard deviation), as well as the median of the semiquantitative scores of the thoracic and abdominal segments. Values for the abdominal aorta showed a smaller diameter and greater extent of atherosclerosis than those for
Table 2 - Mean and standard deviation of the diameters and percentage of medial layer atrophy, as well as median of the semiquantitative scores of the thoracic and abdominal segments of the aorta

\begin{tabular}{llll}
\hline & Thoracic aorta & Abdominal aorta & $P$ value \\
\hline Diameter $(\mathrm{cm})$ & $2.03 \pm 0.19$ & $1.56 \pm 0.30$ & $<.001 *$ \\
Plaque & 4 & 4 & $.07 \dagger$ \\
Calcification & 2 & 3 & $.99 \dagger$ \\
Ulceration & 1 & 2 & $.08 \dagger$ \\
Thrombosis & 1 & 2 & $.29 \dagger$ \\
$\sum$ macro scores & 8 & 10 &. $\mathbf{0 2} \dagger$ \\
Fat & 2 & 2 & $.99 \dagger$ \\
$\%$ Atrophy & $54.9 \pm 17.4$ & $81.2 \pm 17.6$ & $<.001 *$ \\
\hline
\end{tabular}

$\sum$ macro scores $=$ sum of the macroscopic scores; $*$ Paired $t$ test;

$\dagger$ Wilcoxon test.

the thoracic aorta, as indicated by the sum of the macroscopic scores and the percentage of medial layer atrophy.

Table 3 presents the correlation coefficients and $P$ values of the univariate analysis (linear regression) for the diameters of the thoracic and abdominal segments of the aorta versus gender, age, and morphological variables. The diameter of the thoracic, but not the abdominal aorta, correlated positively with age, extent of atherosclerotic plaque, calcification, sum of macroscopic scores, and fat score. Multivariate analysis (multiple linear regression) revealed that age $(P=.06)$ and calcification score $(P=.001)$ were 
Table 3 - Linear correlation (univariate analysis) of the diameters of the thoracic and abdominal segments of the aorta, gender, age, and scores attributed to morphologic variables

\begin{tabular}{lll}
\hline & Thoracic aorta diameter & Abdominal aorta diameter \\
\hline Gender & $\mathrm{r}=0.06(P=.82)$ & $\mathrm{r}=0.32(P=.18)$ \\
Age & $\mathbf{r}=\mathbf{0 . 5 6}(\boldsymbol{P}=\mathbf{. 0 1})$ & $\mathrm{r}=0.22(P=.37)$ \\
Plaque & $\mathbf{r}=\mathbf{0 . 5 9}(\boldsymbol{P}=\mathbf{. 0 0 8})$ & $\mathrm{r}=0.21(P=.39)$ \\
Calcification & $\mathbf{r}=\mathbf{0 . 7 5}(\boldsymbol{P}<. \mathbf{0 0 1})$ & $\mathrm{r}=0.08(P=.74)$ \\
Ulceration & $\mathrm{r}=0.24(P=.31)$ & $\mathrm{r}=0.29(P=.23)$ \\
Thrombosis & $\mathrm{r}=0.01(P=.96)$ & $\mathrm{r}=0.30(P=.21)$ \\
$\begin{array}{l}\text { F macro scores } \\
\text { Fat }\end{array}$ & $\mathbf{r}=\mathbf{0 . 6 3}(\boldsymbol{P}=\mathbf{. 0 0 4})$ & $\mathrm{r}=0.03(P=.90)$ \\
\% Atrophy & $\mathbf{r}=\mathbf{0 . 4 8}(\boldsymbol{P}=\mathbf{. 0 4})$ & $\mathrm{r}=0.41(P=.08)$ \\
\hline
\end{tabular}

$\sum$ macro scores $=$ Sum of the macroscopic scores.

the variables with the strongest associations to the diameter of the thoracic aorta, but no variable was associated with the diameter of the abdominal aorta. Scatter plot graphs of the thoracic aorta diameter versus age and calcification score are presented in Figures 2 and 3.

Regarding gender differences, no significant difference was found concerning age, diameter, semiquantitative scores, or percentage of medial layer atrophy of the thoracic and abdominal segments of the aortas from male patients compared with those from female patients.

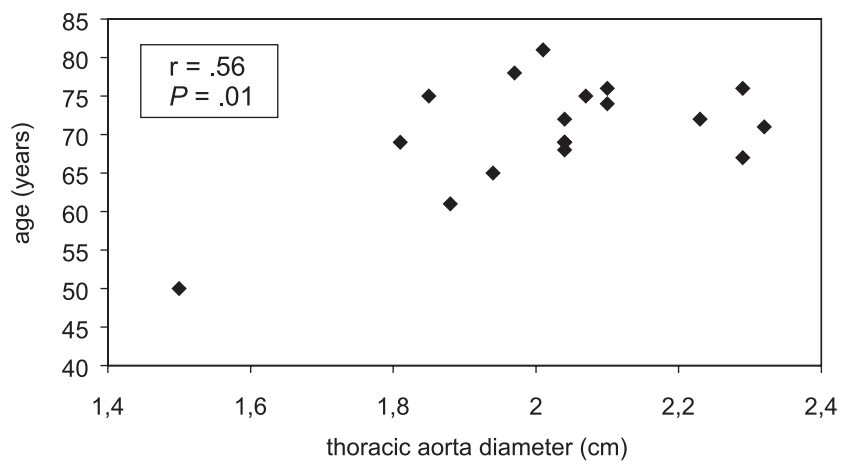

Figure 2 - Scatter plot graph of the diameter of the thoracic aorta versus the age of the patients

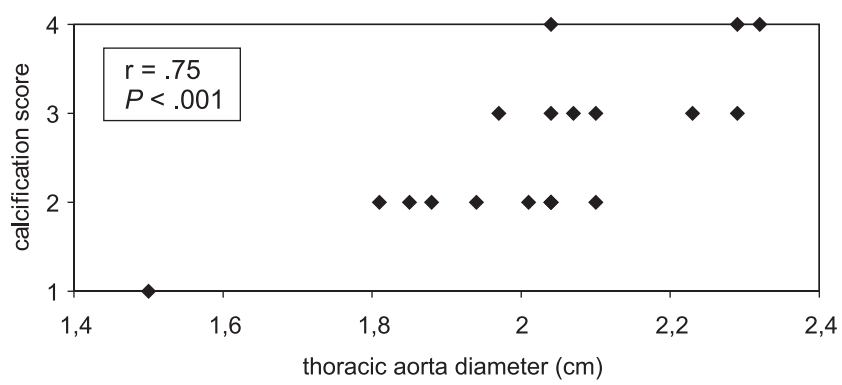

Figure 3 - Scatter plot graph of the diameter of the thoracic aorta versus calcification score

\section{DISCUSSION}

In the present study, we tried to ascertain whether there was any correlation between the aortic diameter and the extent of atherosclerosis, both in thoracic and abdominal segments, in patients who died due to atherosclerotic disease. Previous reports have noted a direct correlation between the aortic diameter, both in thoracic and abdominal segments, and the age of the patient and extent of atherosclerosis. ${ }^{8-10}$ However, these studies focused on the general population instead of patients presenting atherosclerotic disease in attempts to elucidate the mechanisms involved in the pathogenesis of aortic aneurysm.

On the other hand, progressive dilation of the aorta with aging and progression of atherosclerotic lesions does not explain why some patients develop a different, clinically significant spectrum of atherosclerotic disease, namely obliterative atherosclerosis, in which there is reduction of the arterial diameter associated with decrease in blood flow and chronic ischemia of lower limbs. ${ }^{11}$

Similarly with previous reports, we detected a greater extent of atherosclerosis in the abdominal compared with the thoracic aorta. However, whereas there was positive correlation between the diameter of the thoracic aorta and several of the measured parameters, in the abdominal aorta there was no significant correlation between the diameter of the abdominal aorta and any of the measured parameters. Interestingly, multiple linear regression revealed that age and calcification score were the variables with the strongest association with the diameter of the thoracic aorta.

Our results suggest that atherosclerosis in the thoracic segment of the aorta is closely associated with fat deposition within the plaques, resulting in positive remodeling of the vessel. On the other hand, in the abdominal segment, atherosclerosis may or may not be associated with fat deposition. In the case where atherosclerosis is associated with fat deposition, there would be positive remodeling of the vessel with arterial dilation, which could be related to the genesis of aneurysm; conversely, in the case where it is not associated with fat deposition, plaques would have more fibrosis and calcification, and the increased rigidity of the wall would prevent compensatory dilation, thus originating the obliterative form of the disease.

This dualistic behavior of severe atherosclerosis has already been described for the coronary arteries, in which positive remodeling is associated with a large amount of fat in the plaques and myocardial infarction, while the absence of compensatory dilation is associated with fibrous plaques and chronic myocardial ischemia. ${ }^{6,7}$

In summary, our findings suggest that atherosclerosis has distinct features in the thoracic as compared to the ab- 
dominal segments. In the thoracic aorta, the disease is more likely to be associated with deposition of fat within the plaques and positive remodeling. In the abdominal segment, atherosclerosis is less likely to be associated with fat depo- sition and compensatory dilation, thus explaining the development of the obliterative form of the disease, with the significant reduction of the arterial diameter and chronic distal ischemia.

\section{RESUMO}

Benvenuti LA, Onishi RY, Gutierrez PS, Higuchi M de L. Diferentes padrões de remodelamento aterosclerótico na aorta torácica e abdominal. Clinics. 2005;60(5):355-60.

OBJETIVO: Estabelecer relações entre o diâmetro vascular e a intensidade e características histológicas da aterosclerose, nos segmentos torácico e abdominal da aorta. MÉTODO: Foi medido o diâmetro vascular e avaliada a porcentagem de atrofia da camada média da aorta torácica e abdominal de 19 pacientes que faleceram devido a doença aterosclerótica. A presença de placas, calcificação, ulceração, trombose e a quantidade de gordura das placas foi avaliada, semiquantitativamente, nas mesmas regiões.

RESULTADOS: A aterosclerose foi mais intensa na aorta abdominal que na torácica, conforme demonstrado pela maior soma dos escores macroscópicos $(p=0,02)$ e pela maior porcentagem de atrofia da camada média $(p<0,001)$. $\mathrm{O}$ diâmetro da aorta torácica, porém não o da abdominal apresentou correlação positiva com a idade $(\mathrm{r}=0,56 ; p=$ $0,01)$, escore de placa $(\mathrm{r}=0,59 ; p=0,008)$, escore de calcificação $(\mathrm{r}=0,749 ; p<0,001)$ e escore de gordura ( $\mathrm{r}$ $=0,48 ; p=0,04)$. O modelo de regressão linear múltipla evidenciou que as variáveis mais associadas ao diâmetro da aorta torácica foram a idade $(p=0,06)$ e o escore de calcificação $(p=0,001)$.

CONCLUSÃO: A aterosclerose apresenta algumas características distintas nos segmentos torácico e abdominal da aorta. A progressão da aterosclerose na aorta torácica associa-se à deposição de gordura nas placas, ocorrendo dilatação arterial. Na aorta abdominal a aterosclerose pode apresentar evolução semelhante ou estar relacionada à menor deposição de gordura na parede arterial, que se tornaria mais rígida, impedindo a dilatação compensatória.

UNITERMOS: Aorta. Aterosclerose. Diâmetro arterial. Remodelamento. Morfometria.

\section{REFERENCES}

1. Glagov S, Zarins C, Giddens DP, Ku DN. Hemodynamics and atherosclerosis. Insights and perspectives gained from studies of human arteries. Arch Pathol Lab Med. 1988;112:1018-31.

2. Strong JP. Atherosclerotic lesions. Natural history, risk factors, and topography. Arch Pathol Lab Med. 1992;116:1268-75.

3. Thubrikar MJ, Robicsek F. Pressure-induced wall stress and atherosclerosis. Ann Thorac Surg. 1995;59:1594-1603.

4. Zarins CK, Weisenberg E, Kolettis G, Stankunavicius R, Glagov S Differential enlargement of artery segments in response to enlarging atherosclerotic plaques. J Vasc Surg. 1988;7:386-94.
5. Labropoulos N, Zarge J, Mansour MA, Kang SS, Baker WH. Compensatory enlargement is a common pathobiologic response in early atherosclerosis. Am J Surg. 1998;176:140-3.

6. Bezerra HG, Higuchi ML, Gutierrez PS, Palomino SA, Silvestre JM, Libby P, et al. Atheromas that cause fatal thrombosis are usually large and frequently accompanied by vessel enlargement. Cardiovasc Pathol. 2001;10:189-96.

7. Higuchi ML, Gutierrez OS, Bezerra HG, Palomino AS, Aiello VD, Silvestre JM, et al. Comparison between adventitial and intimal inflammation of ruptured and nonruptured atherosclerotic plaques in human coronary arteries. Arq Bras Cardiol. 2002;79:20-24. 
Benvenuti LA et al.

8. Pearce WH, Slaughter MS, LeMaire S, Salyapongse NA, Feinglass J, McCarthy WJ, et al. Aortic diameter as a function of age, gender, and body surface area. Surgery. 1993;114:691-7.

9. Silva ES, Rodrigues AJ, Tolosa EMC, Pereira PRB, Zanoto A. Variation of infrarenal aortic diameter: a necropsy study. J Vasc Surg. 1999; 29:920-7.
10. Zarins CK, Xu C, Glagov S. Atherosclerotic enlargement of the human abdominal aorta. Atherosclerosis. 2001;155:157-64.

11. Hoogendam IJ, Van Rinsum AC, Olyslager J. The diameter of the distal abdominal aorta and the aetiology of local atheroma. J Cardiovasc Surg. 1984;25:408-13. 